\title{
The Influence of Grit, Goal Setting, and Social Support When Starting a Fashion Business
}

\author{
Valerie L McGehee* \\ University of Louisiana, USA
}

*Corresponding author: Valerie L McGehee, Interim Director, Sales and Research

Lab, University of Louisiana at Lafayette, BI Moody III College of Business, USA.

Received Date: September 13, 2019

Published Date: September 16, 2019

\section{Abstract}

The key to surviving the first year of your new business consists of three indispensable traits: grit, goal-setting, and social support. Creative ideas are vital in the beginning steps of forming a new business, but creative minds often lack business acumen, or the organizational skillset needed to persevere. However, when grit, goal-setting, and social support are utilized as major tenets of business planning, the business has a better chance of succeeding. Changing the perspective of failure as an opportunity to learn is an important element of growth mindset in any startup.

Keywords: Grit; Goal setting; Social support; Business; Fashion

\section{Introduction}

What does it take to start a business? Not everyone has the business sense to keep their company afloat. Most creative people have great ideas that would make a thriving business, but they do not know how to run one. It is never a good idea to start a company without passion for your idea. People can go far with passion and perseverance, but it takes more than that. As a former business owner and designer of a swimwear company, I began my fashion line when I was taking MBA courses at Seton Hall University. The professors preached about what it takes to start a business, and the consistent advice was to do what you are passionate about. Passion, however, can only take you so far. Much more discipline and knowhow is needed to build a successful business and to sustain it.

\section{Discussion}

Many will say that half of all new businesses fail, but this is simply not true. From 2016 to 2017, four out of five businesses (about 80\%) survived their first year [1]. According to CB Insights [2], the top five reasons startups fail are: no market need (42\%), ran out of cash (29\%), not the right team (23\%), get outcompeted (19\%), and pricing/cost issues (18\%). How is it that $80 \%$ of new business owners beat these odds and $20 \%$ failed? Three factors play an integral role when it comes to motivational achievement and success: grit, goal setting, and social support. Grit is the tendency to sustain interest in and effort toward very long-term goals [3].
It can be very exciting to be in fashion school and want to embark on new designs and creations. It is those that can endure the trials and tribulations of the stress, financials, and the rollercoaster ride of the losses and successes of owning a business. However, there are two levels of grit. "On average, individuals who are gritty are more self-controlled, but the correlation between these two traits is not perfect: Some individuals are paragons of grit but not selfcontrol, and some exceptionally well-regulated individuals are not especially gritty" [4]. Furthermore, this leads to another degree of grit. We cannot discuss grit, without mentioning growth mindset. Carol Dweck [5] coined the term growth mindset, which is the belief that your abilities can be developed [6]. Part of creating a startup is failing. If one can learn from their mistakes, they can grow as an entrepreneur, as a designer, as a business owner. It is when one is overcome with frustration where they lose steam and give up. Those with a fixed mindset will fail, and those with a growth mindset will endure. Gritty entrepreneurs take smart and thought out chances. They are eager, but steady. For example, one entrepreneur may choose to develop an e-commerce and gain capital as sales increase. Another entrepreneur may throw their money into opening a brick and mortar store and discover the hard way that costs are too expensive to withstand. The entrepreneur that does their research, who is proactive, and who sets goals, will most likely make it pass their first year. 
Goal setting is vital for entrepreneurs to avoid first year failure. Take the time to create a plan, whether this be an official business plan or a Gant chart that is posted in the office. "The major finding of goal setting, which is based on hundreds of studies, is that individuals who are provided with specific, difficult but attainable goals perform better than those given easy, nonspecific, or no goals at all," [7]. When starting a fashion line, it is important to decide the direction in which the business and brand will be in six months, one year, five years, and so on. Creating a timeline of deadlines and goals for sales, bringing on team members and employees, or adding new merchandise, is essential to keeping oneself on task. It is very easy for a creative mind to expand in many directions. Keeping to one's goals can make or break a business.

Lastly is the discussion around social support. It is so easy to forget about the people around us that support us and push us to make our dreams a reality. Surrounding oneself with the right people within the business is paramount for one's emotional stability, especially during stressful times. Creating a company culture of like-minded support can also lead to an environment of positivity. "Social support can take various forms, including emotional support (attempts to alleviate negative affects), professional support (mentoring and guidance), and practical support (money or help with task completion)" [8]. It is necessary to have friends that support your dreams, mentors to help develop your plans, and advisors to guide your financials. It is prideful to work independently because it proves one is capable, but it is wiser to work interdependently for greater success.

\section{Conclusion}

Starting a fashion brand is exciting and can be the best time of your life. However, it is necessary to not allow yourself to be overtaken with eagerness or allow obstacles to deter you or negatively affect the momentum you once had. Learn from these trials and tribulations and grow from the failures you will inevitably face. Slow and steady wins the race. Grit, goal setting and social support is like a three-legged table. Without one of them the table will fall.

\section{Acknowledgement}

None.

\section{Conflict of Interest}

The author declares no conflict of interest.

\section{References}

1. Small Business Administration (2018) Frequently asked questions. About Small Business.

2. CB Insights (2018) The Top 20 Reasons Startups Fail. From lack of product-market fit to disharmony on the team, we break down the top 20 reasons for startup failure by analyzing 101 startup failure postmortems.

3. Duckworth AL, Peterson C, Matthews MD, Kelly DR (2007) Grit: Perseverance and passion for long-term goals. J Pers Soc Psychol 92(6): 1087-1101.

4. Duckworth AL, Gendler TS, Gross JJ (2014) Self-control in school-age children. Educational Psychologist 49(3): 199-217.

5. Dweck C (2015) Talks at Google.

6. France S (2016) The Fixed Mindset vs. The Growth Mindset.

7. Lunenburg F (2012) Goal-setting theory of motivation. International journal of management, business, and administration 15(1): 1-5.

8. Jairam D, Kahl D (2012) Navigating the doctoral experience: The role of social support in the successful degree completion. International journal of doctoral studies 7: 312-329. 